\title{
Feeding patterns of molestus and pipiens forms of Culex pipiens (Diptera: Culicidae) in a region of high hybridization
}

\author{
Bruno Gomes ${ }^{1,2}$, Carla A Sousa ${ }^{1,3}$, José L Vicente ${ }^{1,2}$, Leonor Pinho ${ }^{1,3}$, Isabel Calderón ${ }^{1,2}$, Eliane Arez ${ }^{1,2}$,
} António PG Almeida ${ }^{1,3}$, Martin J Donnelly ${ }^{4}$ and João Pinto ${ }^{1,2^{*}}$

\begin{abstract}
Background: Two biological forms of the mosquito Culex pipiens s.s., denoted pipiens and molestus, display behavioural differences that may affect their role as vectors of arboviruses. In this study, the feeding patterns of molestus and pipiens forms were investigated in Comporta (Portugal), where high levels of inter-form admixture have been recorded.

Methods: Indoor and outdoor mosquito collections were performed in the summer of 2010. Collected Cx. pipiens s.l. females were molecularly identified to species and form by PCR and genotyped for six microsatellites. The source of the blood meal in post-fed females was determined by ELISA and mitochondrial DNA sequencing.

Results: The distribution of the forms differed according to the collection method. The molestus form was present only in indoor collections, whereas pipiens and admixed individuals were sampled both indoors and outdoors. In both forms, over 90\% of blood meals were made on avian hosts. These included blood meals taken from Passeriformes (Passer domesticus and Turdus merula) by females caught resting inside domestic shelters.

Conclusion: Genetic structure and blood meal analyses suggest the presence of a bird biting molestus population in the study area. Both forms were found to rest indoors, mainly in avian shelters, but at least a proportion of females of the pipiens form may bite outdoors in sylvan habitats and then search for anthropogenic resting sites to complete their gonotrophic cycle. This behaviour may potentiate the accidental transmission of arboviruses to humans in the region.
\end{abstract}

Keywords: Culex pipiens, Molestus, Hybridization, Host preferences, Resting behaviour

\section{Background}

Culex pipiens sensu stricto is a major vector of Japanese encephalitis serogroup arboviruses to their natural hosts, which are birds [1] and in the accidental bridgetransmission from birds to humans and domestic mammals [2,3]. This serogroup includes West Nile virus (WNV) and Usutu virus for which human cases have been reported in the European continent $[4,5]$.

\footnotetext{
* Correspondence: jpinto@ihmt.unl.pt

'Unidade de Parasitologia Médica, Instituto de Higiene e Medicina Tropical, Universidade Nova de Lisboa, Rua da Junqueira 100, 1349-008, Lisboa, Portugal

${ }^{2}$ Centro de Malária e outras Doenças Tropicais, Instituto de Higiene e Medicina Tropical, Universidade Nova de Lisboa, Rua da Junqueira 100, 1349-008, Lisboa, Portugal

Full list of author information is available at the end of the article
}

Culex pipiens s.s. is a synanthropic mosquito with a widespread distribution in temperate regions [6]. This species occurs as two biological forms, named molestus and pipiens, which exhibit important behavioural and physiological differences. The molestus form is stenogamous (mates in confined spaces, i.e. $<0.1 \mathrm{~m}^{3}$; [7]), autogenous (can oviposit without a blood meal), homodynamic (remains active during winter) and mammophilic (prefers to feed on mammals, including humans). In contrast, the pipiens form is eurygamous (mates in open spaces), anautogenous (oviposition requires a blood meal), heterodynamic (undergoes winter diapause) and ornithophilic (feeds predominantly on birds) $[8,9]$.

The degree of synanthropy also varies between forms. The molestus form is more restricted to habitats with

\section{Biomed Central}


human influence, whereas the pipiens form has a greater ecological plasticity [6]. In northern temperate latitudes, molestus populations are confined to underground habitats, whereas the pipiens form occupies above ground habitats $[6,10,11]$. In southern Europe and in the Mediterranean region, populations of both forms occur sympatrically in aboveground habitats $[12,13]$.

Hybridization between Cx. pipiens s.s. forms has been considered a major factor influencing WNV transmission [2]. Hybridization between molestus and pipiens may result in a catholic feeding behaviour thereby increasing the risk of admixed populations to act as bridge-vectors of WNV between birds and humans [14]. An influence of different molestus and pipiens genetic backgrounds on host preference has been previously documented [15]. The increase of $C x$. pipiens s.s. bites on mammals, including humans, at the end of summer in the USA, has been attributed to a peak of hybrids in above ground habitats in this period [16]. However, a reduction of bird populations in the region at the end of the summer (specifically the American robin, Turdus migratorius L. 1766) may also potentiate a shift of the feeding behaviour in Cx. pipiens s.s. [17].

West Nile virus surveillance studies in Europe have mainly focused on the detection of the virus (or viral antigens) in natural mosquito populations [18-20]. Particular attention has also been given to the blood feeding preferences of these vector populations [21-23]. However, information about the distribution of the $C x$. pipiens s.s. forms and hybridization rates is generally absent from these reports. More importantly, it remains to be determined how hybridization between molestus and pipiens forms can affect certain behaviours that influence pathogen transmission to humans, including blood feeding preferences, and the degree of synanthropy of the mosquito populations.

A previous study carried out in 2005-2006 in Comporta, an estuarine area in south-central Portugal, described above ground sympatric molestus and pipiens populations with incomplete genetic isolation [12]. The region is home to over 240 bird species, including migratory birds that host WNV, such as the European starling (Sturnus vulgaris L. 1758) and the white stork (Ciconia ciconia L. 1758). The interaction of the migratory birds with Cx. pipiens s.s. mosquitoes may establish a WNV enzootic cycle with the infection of resident WNV host birds such as the house sparrow (Passer domesticus L. 1758) and carrion crow (Corvus corone L. 1758) [24,25]. Hybridization rates of 7.6-10.3\% between molestus and pipiens were recorded in this area, providing an opportunity to study the behavioural consequences of admixture between these forms [12].

In the present study, we have characterized the genetic backgrounds of molestus and pipiens in the Comporta region and related these to epidemiologically relevant traits, in particular their blood meal host preferences. Results are discussed with respect to the relative contribution of the forms, and their hybrids, to the establishment of arboviral transmission cycles.

\section{Methods}

\section{Study region and mosquito collection}

The Comporta region (District of Setubal, Portugal; $38^{\circ}$ $22^{\prime} 60^{\prime \prime} \mathrm{N}, 8^{\circ} 46^{\prime} 60^{\prime \prime} \mathrm{W}$ ) is a wet lowland (altitude $<60 \mathrm{~m}$ ) that includes a semi-natural farming ecosystem (rice production and cork-oak forest) and a protected landscape, the national wildlife reserve of Estuário do Sado. The region has a warm temperate climate with hot dry summers and mild winters (class Csa, Köppen Classification System [26]) with monthly averages of mean daily temperature varying between $10^{\circ} \mathrm{C}$ and $21^{\circ} \mathrm{C}$ and daily rainfall between 0.12 and $3.4 \mathrm{~mm}$.

Mosquito collections took place over two weeks in 2010 $\left(19^{\text {th }}-23^{\text {rd }}\right.$ July and $7^{\text {th }}-13^{\text {th }}$ August $)$ in 7 localities of the region (Additional file 1: Table S1). Three sampling methods were used: i) indoor resting collections (IR) were performed inside domestic animal shelters using hand mechanical aspirators and torches. Each animal shelter was inspected for mosquitoes for a period of $10 \mathrm{~min}$; ii) outdoor CDC light trap (Centers for Disease Control [27]) collections, placed in the canopy of trees (CDC-C) and at ground level (CDC-G), were performed overnight between 19:00-09:00; iii) outdoor human landing catches (HLC) were performed between 20:00-23:00 by a team of four collectors using hand mechanical aspirators and torches.

Collected mosquitoes were killed by freezing and identified to species/complex using morphological keys [28]. Freshly blood-fed female mosquitoes obtained by indoor resting and $\mathrm{CDC}$ light trap collections had their abdomens removed and preserved in $20 \mu \mathrm{l}$ EDTA $(0.125 \mathrm{M})$ at $-20^{\circ} \mathrm{C}$ for subsequent blood meal identification. The thorax and head of each blood-fed female was preserved individually at $-20^{\circ} \mathrm{C}$ until DNA extraction. Non blood-fed whole mosquitoes were preserved in the same conditions as the heads and thoraces.

\section{Mosquito DNA extraction and molecular analysis}

DNA was extracted from individual females (whole body or head plus thorax) using a phenol-chloroform method with ethanol precipitation [29]. Each specimen was identified to species by a multiplex PCR assay targeting species-specific polymorphisms in the intron- 2 of the acetylcholinesterase2 (ace-2) gene using primers specific for $C x$. pipiens s.s., $C x$. quinquefasciatus and Culex torrentium [30].

\section{Selection and analysis of microsatellite loci}

The software WHICHLOCI [31] was applied to the microsatellite dataset used by Gomes et al. [12] to determine the genetic backgrounds of molestus and pipiens in Comporta, in order to select a subset of six loci to be 
analysed in this study. Of the 13 microsatellites that were genotyped in Gomes et al. [12], locus CQ11 was excluded due to its linkage with the diagnostic CQ11FL marker (see below). The remaining 12 microsatellite datasets were used to create three samples of 500 simulated individuals (molestus, pipiens and hybrids) to infer, under $10^{5}$ iterations, which combinations of microsatellites allow correct assignment of the simulated individuals with a minimum accuracy of $90 \%$. Bayesian clustering analysis, as implemented by STRUCTURE 2.3.3. [32], was then used to infer population structure in the data set of Gomes et al. [12] with the best six microsatellites and under the same run conditions. The results obtained for the datasets with six and 13 microsatellites were compared to establish the robustness of the analysis with the lowest battery of microsatellite loci (i.e. six).

Microsatellite genotyping was performed by PCR with fluorescently-labelled primers under the same conditions as in Gomes et al. [12]. Amplified products were separated by capillary electrophoresis in a genetic analyser ABI3730 (Applied Biosystems), at Yale DNA Analysis Facility (USA). Fragment sizes and genotypes were scored using the software GeneMarker 1.4. (Softgenetics, USA).

The multiplex PCR assay described by Bahnck \& Fonseca [33] was used to detect a size polymorphism in the $5^{\prime}$ flanking region of the CQ11 microsatellite of $C x$. pipiens $s$. $s$. that differentiates molestus and pipiens forms as well as their hybrids. This marker, here denoted as CQ11FL, differentiates specimens of the pipiens form (200 bp or $350 \mathrm{bp}$ ) from the molestus form (250 bp PCR product) while hybrids exhibit both pipiens and molestus amplicons [33,34]. Given its relatively good performance at the population level in the region [12], this marker was used to label distinct microsatellite-based genetic clusters as belonging to the molestus or pipiens forms.

\section{Blood meal identification}

A Sandwich ELISA protocol [35] was used to identify blood meals of blood-fed indoor resting mosquitoes. Blood meals were tested for the presence of chicken, cow, dog, goat/sheep, horse/donkey, human, pig, and rabbit immunoglobulin G (IgG). Four positive controls (blood from the tested species) and 14 negative controls (two blood samples from the other seven species) were used in every 96-well microplate. Absorbance values were read at $492 \mathrm{~nm}$ wave length in an ELISA reader (Anthos $2010{ }^{\circledR}$, Anthos Labtec Instruments). Cut-off values were calculated for each plate, as the mean plus three times the standard deviation of the negative controls.

Fragments of the mitochondrial DNA cytochrome $b$ $(c y t b)$ gene were sequenced to identify the blood meal source of female mosquitoes collected in the canopy of trees (CDC-C) and for a subsample of females caught indoor resting (ELISA-negative blood meals and random blood meals from all the different types of blood meal identified). DNA extraction from blood samples was performed with the DNeasy Blood \&Tissue Kit (Qiagen, Valencia, CA). The vertebrate $c y t b$ gene was amplified following a modified version of the protocol of Hamer et al. [36] that excluded the fourth primer pair amplification. PCR products were purified with the QIAquick PCR Purification kit (Qiagen) and sequenced in a biotechnology company (StabVida, Oeiras) on an ABI3730XL automated sequencer (Applied Biosystems). Sequences were manually corrected and aligned using BioEdit 7.0.9.0 [37]. Identification of host species was performed by comparison with $c y t b$ sequences deposited at NCBI GenBank.

\section{Data analysis}

Bayesian clustering analysis, as implemented by STRUCTURE 2.3.3. [32], was used to infer population substructure/ancestry from the data set without prior information of sampling groups under the conditions of admixture ( $\alpha$ allowed to vary between 0 and 10), and allele frequencies correlated among populations ( $\lambda$ was set at 1 , default value). Ten independent runs with $10^{4}$ iterations and $10^{5}$ replications were performed for each value of $K(K=1$ to 10 clusters). To infer the most likely number of clusters in the sample, the $\Delta K$ statistic was used [38]. Information from the outputs of each $K$ (10 runs) was compiled by the Greedy method implemented in CLUMPP [39]. Following the suggestions of Vähä \& Primmer [40], individual genetic assignment to clusters was based on a minimum posterior probability threshold $(T q)$ of 0.90 . Individuals displaying $0.1 \leq q_{i} \leq 0.90$ were considered of admixed ancestry.

Genetic diversity at each microsatellite locus was characterised by estimates of expected heterozygosity $\left(H_{e}\right)$ [41] and inbreeding coefficient $\left(F_{I S}\right)$. Significance of $F_{I S}$ values was assessed by randomisation tests. These analyses were performed using FSTAT v. 2.9.3.2. [42]. Estimates of allele richness $\left(A_{R}\right)$, adjusted for the lowest sample size, were obtained by a rarefaction statistical approach implemented by the programme HP-RARE [43]. Departures from Hardy-Weinberg equilibrium were tested by exact tests available in ARLEQUIN v.3.5. [44]. The same software was used to perform exact tests of linkage equilibrium between pairs of loci based on the expectation-maximisation approach described by Slatkin \& Excoffier [45]. The software MICRO-CHECKER 2.2.3. was used to search (99\% confidence interval) for null alleles at loci/samples [46].

Fisher's exact tests $(2 \times 2)$ were performed with "VassarStats: Website for Statistical Computation" [47] to determine associations between the genetic clusters identified by STRUCTURE and the origin of blood meals.

Whenever multiple testing was performed, the nominal significance level of rejection of the null hypothesis 
$(\alpha=0.05)$ was corrected by the sequential Bonferroni procedure [48].

\section{Results}

\section{Mosquito sampling}

A total of 80 IR collections were performed in 28 sites (Table 1). The majority of animal shelters found in the area were chicken coops (46.4\%). Consequently, 44 (55.0\%) of the IR collections were made in chicken coops, whereas $19(23.8 \%)$ were made in shelters harbouring mammalian hosts without domestic birds (i.e. rabbit hutches, cattle barns and pig pens). Seven (8.8\%) collections were performed in shelters with both avian and mammalian hosts and 10 (12.5\%) inside installations without any visible vertebrate host. The IR collections yielded a total of 235 Cx. pipiens s.l. females, of which $174(74.0 \%)$ were blood fed. Of the total of females caught, $88.5 \%$ were sampled inside chicken coops, $4.3 \%$ in mammalian shelters, $3.8 \%$ in mixed avian-mammal shelters and $3.4 \%$ in installations with no domestic vertebrates (Table 1). None of the 10 females caught inside shelters exclusively with mammalian hosts was blood fed and only 6 (3.4\%) engorged females were collected in mixed avian-mammalian shelters.

A total of 24 outdoor CDC light trap collections were performed (Additional file 1: Table S1). Of these, 17 were performed with traps hung in the canopy of trees (CDC-C), yielding 1,093 Cx. pipiens s.l. females, and 7 were placed at ground level yielding a total of 625 females. Human landing catches were performed six times at a single site (Additional file 1: Table S1). These collections yielded a

Table 1 Number of indoor resting collections and Cx. pipiens s.l. mosquitoes caught according to the type of shelter

\begin{tabular}{|c|c|c|c|c|c|}
\hline \multirow[t]{2}{*}{ Shelters } & \multirow{2}{*}{$\begin{array}{c}\text { IR } \\
\text { sites }\end{array}$} & \multicolumn{2}{|c|}{ Collections } & \multicolumn{2}{|c|}{ Cx. pipiens s.I. } \\
\hline & & $N_{C}$ & $N_{P C}$ & $N_{F}$ & $N_{B F}$ \\
\hline \multirow[t]{2}{*}{ Chicken coops } & 13 & 44 & 31 & 208 & 164 \\
\hline & $(46.4)$ & $(55.0)$ & $(70.5)$ & $(88.5)$ & $(94.3)$ \\
\hline \multirow[t]{2}{*}{ Rabbit hutches } & 3 & 11 & 4 & 10 & 0 \\
\hline & $(10.7)$ & (13.8) & $(9.1)$ & $(4.3)$ & $(0.0)$ \\
\hline \multirow[t]{2}{*}{ Cattle barns } & 1 & 4 & 0 & 0 & 0 \\
\hline & (3.6) & $(5.0)$ & $(0.0)$ & $(0.0)$ & $(0.0)$ \\
\hline \multirow[t]{2}{*}{ Pig pens } & 3 & 4 & 0 & 0 & 0 \\
\hline & $(10.7)$ & $(5.0)$ & $(0.0)$ & $(0.0)$ & $(0.0)$ \\
\hline \multirow[t]{2}{*}{ Mixed composition } & 3 & 7 & 5 & 9 & 6 \\
\hline & $(10.7)$ & $(8.8)$ & (11.4) & (3.8) & $(3.4)$ \\
\hline \multirow[t]{2}{*}{ Without vertebrates } & 5 & 10 & 4 & 8 & 4 \\
\hline & (17.9) & $(12.5)$ & $(9.1)$ & (3.4) & (2.3) \\
\hline Total & 28 & 80 & 44 & 235 & 174 \\
\hline
\end{tabular}

IR sites: number of indoor resting collection sites surveyed; $N_{C}$ : number of collections performed; $N_{P C}$ : number of collections positive for $C X$. pipiens s.l.; $N_{F}$ : number of $C x$. pipiens s.l. females collected; $N_{B F}$ : number of blood-fed females collected; Mixed composition: Shelter with domestic birds and domestic mammals. Values in brackets represent relative frequencies (in percentage). total of 155 Cx. pipiens s.l. females. The mean number of bites per human per hour was 2.2 for this species.

\section{Microsatellite analysis}

The best combination of six microsatellites (assigned score of 92.0\%) included loci CxpGT04, CQ26, CxpGT20, CxpGT12, CQ41, and CxpGT40 (Additional file 1: Table S2). The analysis with six loci was able to split the Gomes et al. [12] dataset into two clusters with a highly similar result to that obtained with 13 loci (Additional file 1: Table S3). Taking the 13 loci dataset as the gold standard, the analysis with six loci had an average accuracy (i.e. average of the number of correctly identified individuals for a class over the total number of individuals assigned to that class) of $81.6 \%$ and average power (i.e. average of the number of correctly identified individuals for a class over the actual number of individuals of that class) of $88.6 \%$.

Of the IR collections, only blood-fed females caught inside shelters with vertebrate hosts were selected for molecular genotyping $(N=174)$. Of these, four specimens failed in PCR amplifications and were thus excluded. A total of 170 females from five of the seven localities (Cambado: $N=14$; Comporta: $N=27$; Pego: $N=47$; Possanco: $N=80$; Torre: $N=2$ ) were analysed. In addition to IR mosquitoes, subsamples from CDC-C $(N=39$, of which 9 were blood fed), CDC-G $(N=42)$ and HLC $(N=40)$ were also included, giving a total of 291 specimens used for molecular identification and microsatellite genotyping. All specimens were molecularly identified as Cx. pipiens s.s. by PCR [30].

Bayesian clustering analysis implemented by STRUCTURE revealed two clusters (Figure 1A). Cluster 1 grouped 48 specimens of which $42(87.5 \%)$ were classified as molestus form by the CQ11FL locus (Table 2). The majority $(84.3 \%)$ of the 204 specimens in cluster 2 was classified as pipiens form by CQ11FL (Table 2). There were 39 females exhibiting an admixed ancestry (i.e. $q_{i} \geq 0.10$ for both clusters). Of these, seven (17.9\%) had a heterozygous CQ11FL200/250 genotype while the majority $(N=31$, 79.5\%) were classified as pipiens form by CQ11FL PCR (Table 2). There were twelve individuals displaying a 350 bp CQ11FL allele. Of these, 11 were grouped in the pipiens cluster, while one CQ11FL200/350 heterozygote was assigned to the admixed cluster (Table 2).

Genetic diversity estimates for the 6 microsatellite loci analysed for the whole dataset $(N=291)$ and in subsamples determined by clustering analysis (STRUCTURE) and by sampling type (i.e. collections inside animal shelters versus outdoor collections) are shown in Table S4 (see Additional file 1). Significant departures from Hardy-Weinberg equilibrium were detected at 5 loci $(83.3 \%)$ when all specimens were analysed as a single sample (Additional file 1: Table S4). However, when the sample was subdivided according to clustering assignment and sampling site, significant 


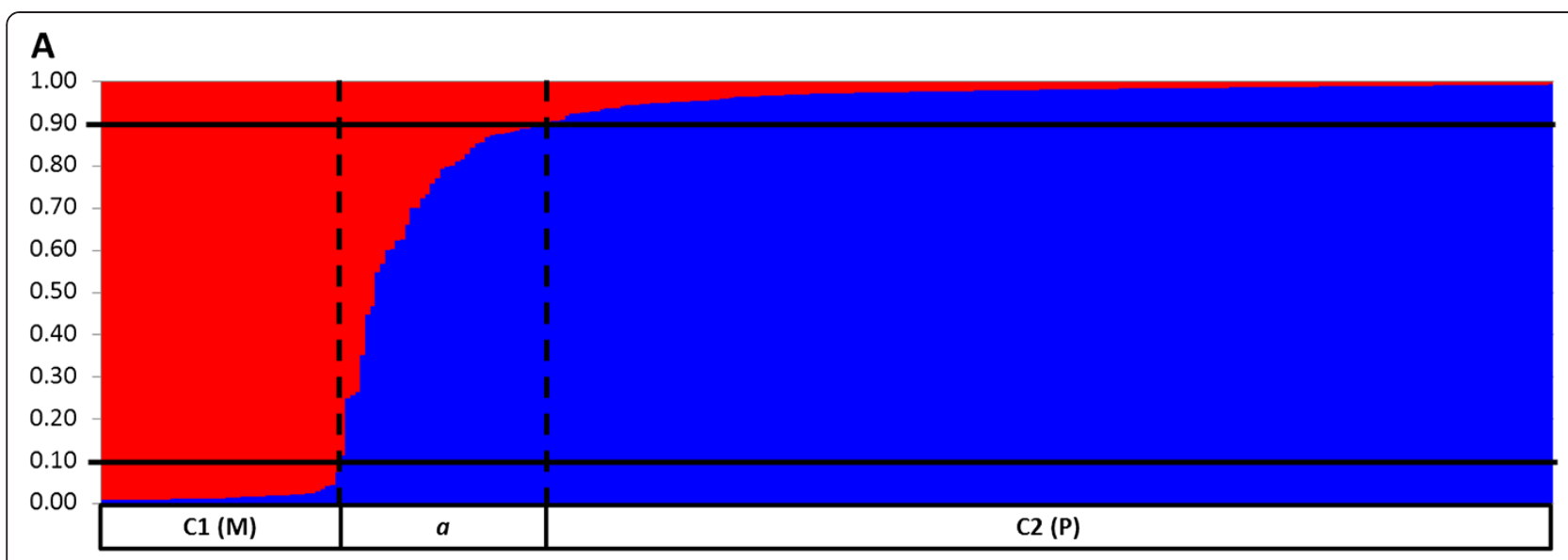

\section{B}

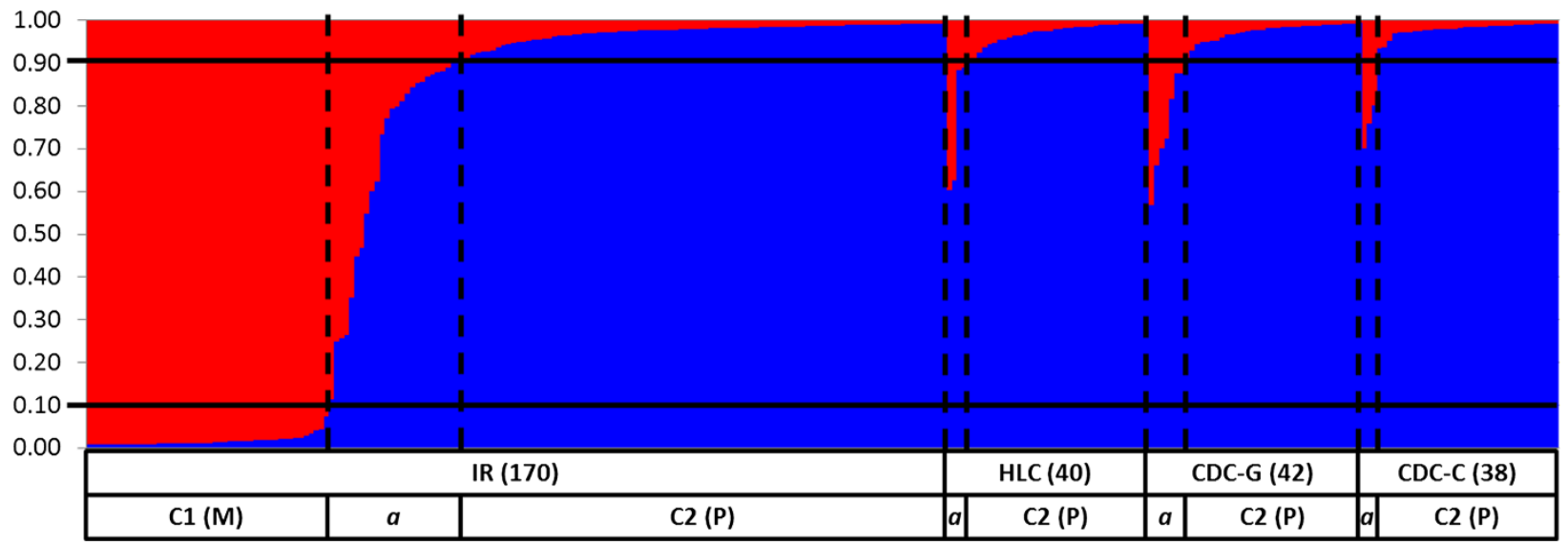

Figure 1 Bayesian cluster analysis of Cx. pipiens s.s. mosquitoes conducted by STRUCTURE in Comporta (2010). A: Individuals sorted by their ancestral probability; B: Individuals sorted by collection method and ancestral probability; IR: indoor resting inside shelters; CDC-G: CDC light traps in ground level; CDC-C: CDC light traps in canopy of trees; HLC: human landing catches; a: admixed individuals $(0.1<T q<0.9)$. Columns correspond to the multilocus genotype of each individual, partitioned in different colours representing the probability of ancestry $\left(q_{i}\right)$ to each cluster (Red: molestus; Blue: pipiens). Individuals were ordered according to their geographic information. Lines indicate the $q_{i}$ threshold used to determine admixed individuals (see Methods).

heterozygote deficits were observed only on six occasions (21.4\% out of 28 tests). These departures were generally associated with significant positive $F_{I S}$ values indicative of a heterozygote deficit. Exact tests of linkage disequilibrium revealed 12 (80.0\%) significant associations between pairs of loci for the whole dataset. When samples were divided by clustering assignment and type of sampling site, only one significant association was observed (1.3\% out of 75 combinations). The analysis performed by MICRO-CHECKER did not find a consistent signal of null alleles in any loci. All microsatellite loci were maintained for subsequent analyses.

Bayesian clustering analysis showed a non-uniform distribution of the forms among collection methods (Figure 1B). All specimens with a molestus genetic background were sampled solely by IR collections, whereas individuals with pipiens or admixed ancestry were collected by both IR and outdoor collections (i.e. CDC-C, CDC-G and HLC). In IR collections, the proportion of
Table 2 Frequencies of molecular identification at the CQ11FL in each of the ancestry clusters revealed by STRUCTURE

\begin{tabular}{|c|c|c|c|c|}
\hline & \multirow[t]{2}{*}{$N$} & \multicolumn{3}{|c|}{ CQ11FL genotype } \\
\hline & & $250 / 250$ & $200 / 250$ & $200 / 200$ \\
\hline \multirow[t]{2}{*}{ Cluster 1 (molestus) } & 48 & 42 & 2 & 4 \\
\hline & & $(87.5)$ & $(4.2)$ & (8.3) \\
\hline \multirow[t]{2}{*}{ Cluster 2 (pipiens) } & $204^{\mathrm{a}}$ & 6 & $25^{\mathrm{b}}$ & $172^{c}$ \\
\hline & & $(2.9)$ & $(12.3)$ & $(84.3)$ \\
\hline \multirow[t]{2}{*}{ Admixed } & 39 & 1 & 7 & $31^{d}$ \\
\hline & & $(2.6)$ & $(17.9)$ & $(79.5)$ \\
\hline \multirow[t]{2}{*}{ Total } & 291 & 49 & 34 & 207 \\
\hline & & $(11.7)$ & $(16.8)$ & $(71.1)$ \\
\hline
\end{tabular}

$N$ : number of individuals; Values in parenthesis refer to the frequencies (in percentage) within each cluster. ${ }^{a}$ includes one specimen without CQ11FL identification. ${ }^{\mathrm{b}}$ includes one CQ11FL250/350 heterozygote. ${ }^{\mathrm{c}}$ includes one CQ11FL350/350 homozygote and nine CQ11FL200/350 heterozygotes.

d includes one CQ11FL200/350. 
molestus individuals caught inside chicken coops was $28.8 \%$ of the total catch and $16.7 \%$ in avian-mammal mixed shelters. The proportion of admixed individuals caught by IR (14.7\%, 25 out of 170) was comparable to that sampled by outdoor collection methods (11.6\%, 14 out of 121).

The distribution of $C x$. pipiens s.s. forms in IR collections appeared not to be homogenous among the localities surveyed (Figure 2). Individuals of molestus ancestry were concentrated mainly in Pego (79.2\%), constituting 80.9\% of the total IR catch at this locality. The proportion of IR collections made at avian shelters (i.e. chicken coops) in Pego was $45.0 \%$, whereas it varied between $61.5 \%$ and 83.3\% in the two localities where the pipiens form predominated (Comporta and Possanco; Figure 2).

\section{Blood meal identification}

Blood meal identification by ELISA revealed that most $(N=159 ; 93.5 \%)$ of the 170 blood feeds analysed were from avian hosts (Table 3). The proportion of blood meals taken on avian hosts by pipiens (95.9\%) and molestus (91.6\%) forms was not significantly different (Fisher's exact test: $P=0.108$; Table 3). All admixed individuals fed on avian hosts. There were only three single blood meals taken on mammalian hosts. All consisted of human blood taken by two molestus and one pipiens females. There were also two females (one molestus and one admixed) with a mixed blood meal with cow and avian blood. The ELISA did not identify the origin of six blood meals (three pipiens, two molestus and one hybrid).

Sequence analysis of the $c y t b$ gene in blood samples was performed for the nine engorged females caught in light traps from the tree canopy (CDC-C) and 19 specimens from IR collections (the six females without ELISA identification, two females with mixed feeds, three females with only mammalian blood, and eight females with only avian blood). Two samples did not amplify $c y t b$ gene of any vertebrate (one molestus female without ELISA identification and one female from the canopy). The $c y t b$ analysis confirmed the ELISA results for the females with single feed but identified only chicken (Gallus gallus L. 1758; GenBank: DQ512918.1) mtDNA in the blood of the two females with mixed feeds. Two bird species were identified in the five females caught IR without ELISA identification: house sparrow (Passer domesticus; GenBank: AY495393.1) in four females (two pipiens, one molestus and one hybrid), and blackbird (Turdus merula L. 1758; GenBank: EU154637.1) in one pipiens female. In the nine females collected by CDC-C, two other bird species were identified: long-eared owl (Asio otus L. 1758; GenBank: AF082067.2) blood in eight females (seven pipiens and one hybrid) and blue tit (Cyanistes caeruleus (L. 1758); GenBank: AF347961.1) blood in one pipiens female.

\section{Discussion}

In this study, a notable difference was found in the distribution of molestus and pipiens forms according to collection methods. While the pipiens form was sampled by all methods, molestus individuals were caught only in IR collections. This result suggests differences between forms in biting and resting behaviours. When placed outdoors, CDC light traps are appropriate for sampling both host seeking mosquitoes and recently blood-fed mosquitoes searching for a suitable resting site [49]. These traps have been successfully used as an alternative to outdoor resting collections in feeding pattern studies of $C x$. pipiens s.l. conducted in the USA [17,50]. The absence of the molestus form from outdoor CDC light trap collections may suggest a more endophagic and endophilic behaviour of this form. A tendency of the molestus form to bite indoors was further highlighted by its absence from outdoor landing catches. These results point to a predominantly indoor and synanthropic behaviour of the molestus form, as described for populations of this form at northern latitudes where inter-form hybridization is rare $[6,10,16]$. Therefore, it appears that in spite of the high hybridization levels and in addition to autogeny and stenogamy, the molestus population of Comporta maintains behavioural phenotypes typical of this form. This observation is consistent with a pure molestus genetic background found in the region, which contrasted with a more introgressed pipiens background [12].

Also compatible with a pattern of asymmetric hybridization, with more molestus genes introgressing the pipiens form, is an apparently more plastic resting behaviour of the pipiens form, suggested by the fact that bloodfed females of this form were collected both indoors and outdoors. However, the number of blood-fed $C x$. pipiens s. $s$. females collected in outdoor CDC light traps (9 out of $1,718)$ was much lower than those in IR collections (174 out of 235). Furthermore, the apparent behavioural differences observed between pipiens and molestus forms should be considered with caution given the sampling design used in this study, which did not include paired collections with the same method. Additional surveys involving paired indoor/outdoor landing catches (to directly evaluate endo/ exophagy) and indoor/outdoor resting collections would be required to confirm these observations.

The approach used for the selection of microsatellites to differentiate molestus and pipiens forms allowed reduction of the number of loci to be genotyped from 13 to 6 whilst maintaining high accuracy and power. The efficiency of multilocus analyses tends to increase with the number of microsatellite [40]. However, the use of a more limited number of loci can benefit their application in surveillance studies by minimising genotyping costs and thus allowing genotyping of larger sampling sizes. Given the importance of accurately determining 


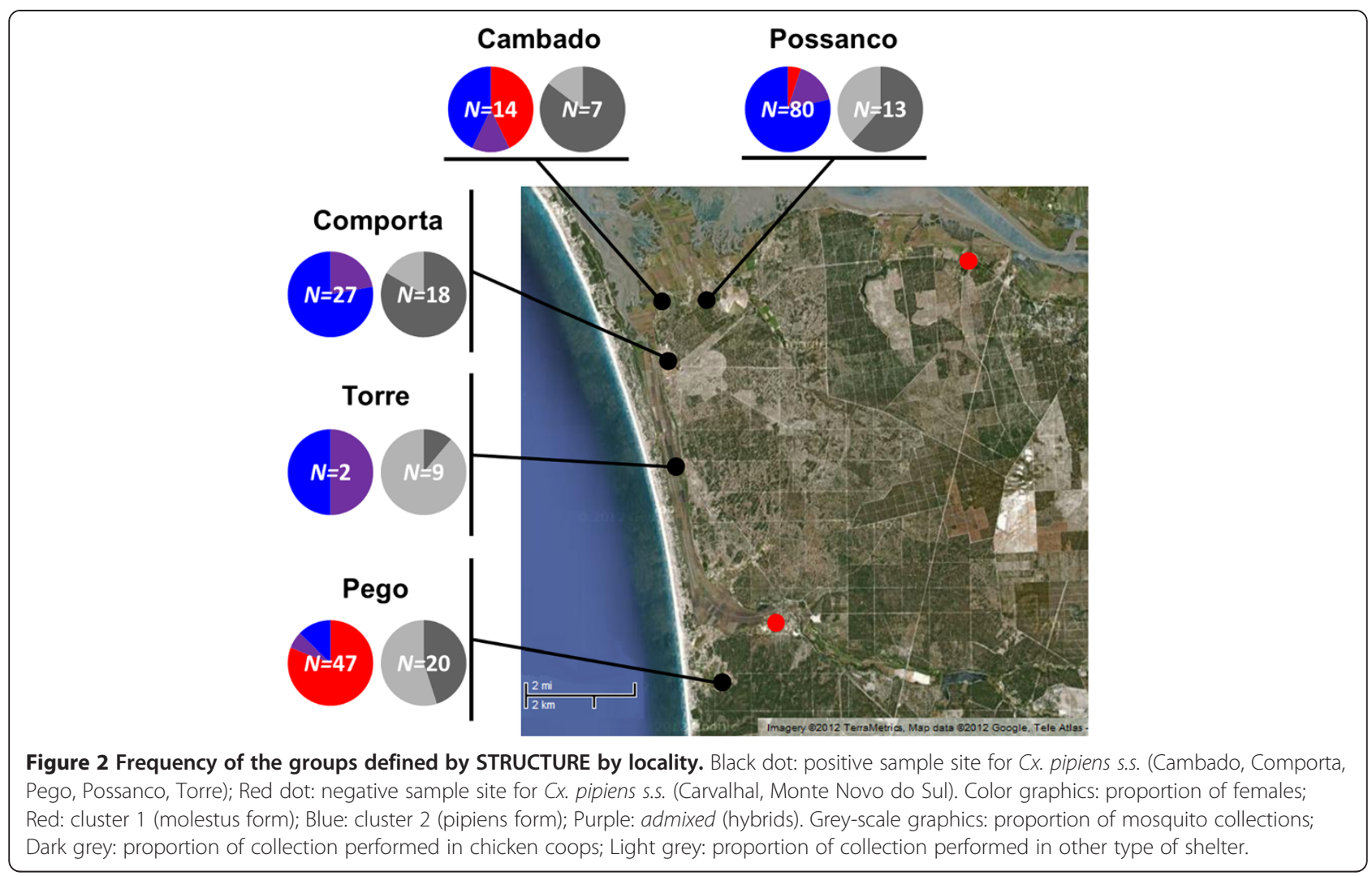

the intra-specific composition of Cx. pipiens s.s. it is recommended that similar microsatellite-based approaches are used in epidemiological surveys to complement the information based on a single marker (CQ11FL) that has limitations in areas of continued introgression $[12,33]$.

As in the survey conducted in 2005-2006 [12], sympatric molestus and pipiens populations displaying high hybridization levels were identified above ground in the region of Comporta. However, a higher proportion of the molestus form was found in a 2005-2006 survey (66.2\%; Gomes et al., 2009), whereas in the present study the pipiens form prevailed (70.1\%). This difference most likely reflects the outdoor sampling carried out in this study and which was not carried out in the previous survey. In addition, the survey of $2005 / 2006$ was mainly concentrated in the locality of Pego (ca. $77 \%$ of females), where $79 \%$ of molestus individuals were collected in the present survey. The reasons for a higher frequency of the molestus form in Pego remain unclear. Although the proportion of chicken coops sampled in this locality was lower than in those localities where the pipiens form predominated, this may not explain the differences since the vast majority (>90\%) of Cx. pipiens s.s. was sampled inside chicken coops in the three localities where the molestus form was detected. Other factors may affect the apparently heterogeneous distribution of the forms, such as the type of animal shelters (e.g. construction materials) or differences in breeding site availability and exploitation. More detailed ecological studies are thus needed to further clarify the presence and determinants of spatial heterogeneities between forms in this region.

Blood meal analysis revealed that the great majority of Cx. pipiens s.s. females fed on avian hosts. The pipiens form showed a slightly higher proportion of avian blood

Table 3 Blood meal source identification (by ELISA) in each of the ancestry clusters revealed by STRUCTURE in indoor collections

\begin{tabular}{cccccc}
\hline & $\boldsymbol{N}$ & \multicolumn{4}{c}{ Blood feed - Indoor } \\
\cline { 3 - 6 } & & Mammal & Bird & Mixed & WI \\
\hline Cluster 1 (molestus) & 48 & 2 & 43 & 1 & 2 \\
Cluster 2 (pipiens) & 97 & 1 & $(89.5)$ & $(2.1)$ & $(4.2)$ \\
Admixed & & $(1.0)$ & $(95.9)$ & $(0.0)$ & $(3.1)$ \\
& 25 & 0 & 23 & 1 & 1 \\
Total & & $(0.0)$ & $(92.0)$ & $(4.0)$ & $(4.0)$ \\
& 170 & 3 & 159 & 2 & 6 \\
& & $(1.8)$ & $(93.5)$ & $(1.2)$ & $(3.5)$ \\
\hline
\end{tabular}

$N$ : number of individuals; Mammal: feeds in mammal (all in Human); Bird: feeds in Bird (chicken antibody); Mixed: Mixed fed in mammal and bird (all in cow and chicken); Wl: without positive identification. Values in parenthesis refer to the frequencies (in percentage) within each cluster. 
feeds when compared with the molestus form. However, this difference was non-significant and the proportion of avian blood meals was above $90 \%$ in both forms, suggesting an ornithophilic tendency for $C x$. pipiens s.s. in the region. Ornithophilic tendency was also observed in a study analysing $C x$. pipiens s.l. from urban and countryside areas of Portugal, in which over $70 \%$ of the females fed on birds [23], and from south-west countryside areas of Spain, where over $80 \%$ of the females fed on birds [22]. The pipiens form has been described as ornithophilic, whereas molestus populations were recognised as being mammophilic $[8,9]$. However, the feeding patterns of Cx. pipiens s.s. populations depend not only on their genetic background but also on the availability of vertebrate hosts and on host defensive mechanisms [15,21]. Consequently, exceptions to the general feeding pattern have been reported for both forms in the USA and in the Mediterranean region [15,51,52]. Furthermore, hybridization between the two forms may also promote a more opportunistic feeding behaviour in Cx. pipiens s.s. [2]. Such a catholic behaviour would thus increase the relative importance of host availability and host defensive mechanisms in the feeding pattern of the mosquito population. Therefore, continued hybridization between forms coupled with a greater availability of avian hosts in the study area may explain the greater proportion of avian feeds taken by the molestus population, which is otherwise considered as being mammophilic.

While molestus and pipiens appear to be mainly ornithophilic in the Comporta region, this may reflect host availability in the region rather than an intrinsic host preference. A lower availability of mammals (including humans) is suggested by a higher proportion of chicken coops (46.4\%) when compared to mammalian shelters without domestic birds (25.0\%), and by the well-built and protected human dwellings with door and window screens that prevent mosquito entry [53]. On the other hand, pipiens form mosquitoes were caught biting humans outdoors in HLC collections which play in favour of a more opportunistic feeding pattern promoted by hybridization. Altogether, these findings suggest a closer association of both molestus and pipiens forms with avian hosts and that this ornithophilic tendency, albeit possibly genetically conditioned, may be mainly determined by host availability in the region. In this scenario, molestus females, with a preference for biting mammalian hosts, may feed more readily on the available bird hosts, which may increase the odds for alternate feeding on birds and mammals. This feeding behaviour may increase the risk of WNV transmission from birds, which are natural amplification hosts, to accidental hosts such as humans and domestic mammals.

It is worth noting, however, that the two mosquito collections carried out in this study took place in midsummer. This did not allow inference on the possible seasonal variations in the feeding patterns of the forms, which may vary through time due to factors such as temperature and bird migration [17]. Further studies, involving longitudinal sampling, will be required to further clarify the intrinsic host preference of $C x$. pipiens forms in the region and if host availability is the main factor modulating the feeding patterns over time, in a similar manner to what has been observed in the USA [17].

Blood meal host identification based on mtDNA sequencing identified bird species from Passeriformes and Strigiformes orders. Birds from these orders were identified with anti-WNV antibodies in Portugal indicating the circulation of WNV in these populations [54]. The Passeriformes are a well-known WNV reservoir [55,56]. Species of this order, such as Passer domesticus, displayed the highest WNV prevalence in USA [36,57].

\section{Conclusion}

The presence of females from both forms collected inside domestic animal shelters with a blood meal taken from wild Passeriformes gives a clear indication of the proximity between the WNV natural cycle and the human population in the Comporta region. Species such as the house sparrow and the blackbird have tolerance for humans and the blood meal could have been taken indoors when those birds enter in human constructions searching for food or shelter. However, the combination of the genetic structure and blood meal analysis suggest that at least a proportion of pipiens form females may bite outdoors in sylvan habitats and then search for anthropogenic indoor resting sites to complete their gonotrophic cycle. In both scenarios, alternative domestic hosts and humans are available in those sites for subsequent blood feeding, which may promote the accidental transmission of WNV and other arboviruses in this region.

\section{Additional file}

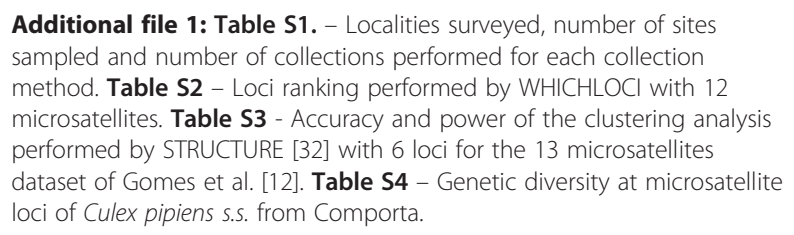

Additional file 1: Table S1. - Localities surveyed, number of sites sampled and number of collections performed for each collection method. Table S2 - Loci ranking performed by WHICHLOCI with 12 microsatellites. Table S3 - Accuracy and power of the clustering analysis performed by STRUCTURE [32] with 6 loci for the 13 microsatellites dataset of Gomes et al. [12]. Table S4 - Genetic diversity at microsatellite loci of Culex pipiens s.s. from Comporta.

\section{Abbreviations}

ace-2: acetylcholinesterase-2 gene; $A_{R}$ : allelic richness; bp: base pair; ca.: circa; CDC-C: Centers for Disease Control light trap placed in the canopy of trees; CDC-G: Centers for Disease Control light trap placed at ground level; CQ11FL: molecular assay in the 5' flanking region of the CQ11 microsatellite; Csa: temperate climate with dry and hot summers; CX: Culex; cyt b: cytochrome b; DNA: deoxyribonucleic acid; dNTPs: deoxynucleotide triphosphates; EDTA: ethylenediaminetetraacetic acid; ELISA: enzyme-linked immunosorbent assay; et al:: et alli; $F_{I S}$ : inbreeding coefficient; $F_{S T}$ : fixation 
index; i.e.: id est; IgG: immunoglobulin G; He: expected heterozygosity; HLC: human landing catches; IR: indoor resting collections; $K$ : number of clusters; L.: Linnaeus; min: minutes; mtDNA: mitochondrial deoxyribonucleic acid; N: sample size; NCBI: National Center for Biotechnology Information; $P$ : probability; PCR: polymerase chain reaction; $q_{i}$ : probability of ancestry; $s$. I.: sensu lato; s.s.: sensu stricto; Tq: posterior probability threshold; USA: United States of America; WNV: West Nile virus; $a$ : nominal significance level of rejection of the null hypothesis; $\Delta \mathrm{K}$ : ad hoc approach to infer the most likely number of clusters in the sample by the STRUCTURE.

\section{Competing interests}

The authors declare that they have no competing interests.

\section{Authors' contributions}

BG, CAS, JLV, LP and IC carried out sample collections. Molecular analyses were conducted by BG, JLV and EA. BG and JP performed the genetic data analysis. BG, CAS, APGA, MJD and JP conceived the study and designed the experiments. BG and JP drafted the manuscript with the contributions of CAS, APGA and MJD. All authors read and approved the final manuscript.

\section{Acknowledgments}

This study was funded by Fundação para a Ciência e a Tecnologia/FEDER, Portugal (POCI/BIA-BDE/57650/2004 and PPCDT/BIA-BDE/57650/2004). BG was funded by a PhD fellowship of Fundação para a Ciência e Tecnologia/ FEDER (SFRH/BD/36410/2007).

\section{Author details}

${ }^{1}$ Unidade de Parasitologia Médica, Instituto de Higiene e Medicina Tropical, Universidade Nova de Lisboa, Rua da Junqueira 100, 1349-008, Lisboa, Portugal. ' Centro de Malária e outras Doenças Tropicais, Instituto de Higiene e Medicina Tropical, Universidade Nova de Lisboa, Rua da Junqueira 100, 1349-008, Lisboa, Portugal. ${ }^{3}$ Unidade de Parasitologia e Microbiologia Médicas, Instituto de Higiene e Medicina Tropical, Universidade Nova de Lisboa, Rua da Junqueira 100, 1349-008, Lisboa, Portugal. ${ }^{4}$ Department of Vector Biology, Liverpool School of Tropical Medicine, Pembroke Place, Liverpool L3 5QA, UK.

Received: 9 January 2013 Accepted: 22 March 2013

Published: 11 April 2013

\section{References}

1. Medlock JM, Snow KR, Leach S: Potential transmission of West Nile virus in the British Isles: an ecological review of candidate mosquito bridge vectors. Med Vet Entomol 2005, 19:2-21.

2. Fonseca DM, Keyghobadi N, Malcolm CA, Mehmet C, Schaffner F, Mogi M, Fleischer RC, Wilkerson RC: Emerging Vectors in the Culex pipiens Complex. Science 2004, 303:1535-1538.

3. Hamer GL, Kitron UD, Brawn JD, Loss SR, Ruiz MO, Goldberg TL, Walker ED: Culex pipiens (Diptera: Culicidae): a bridge vector of West Nile virus to humans. J Med Entomol 2008, 45:125-128.

4. Zeller HG, Schuffenecker I: West Nile virus: an overview of its spread in Europe and the Mediterranean basin in contrast to its spread in the Americas. Eur J Clin Microbiol Infect Dis 2004, 23:147-156.

5. Calzolari M, Gaibani P, Bellini R, Defilippo F, Pierro A, Albieri A, Maioli G, Luppi A, Rossini G, Balzani A, Tamba M, Galletti G, Gelati A, Carrieri M, Poglayen G, Cavrini F, Natalini S, Dottori M, Sambri V, Angelini P, Bonilauri P: Mosquito, bird and human surveillance of West Nile and usutu viruses in Emilia-Romagna region (Italy) in 2010. PLOS ONE 2012, 7:e38058.

6. Vinogradova AN: Culex pipiens pipiens mosquitoes:Taxonomy, Distribution, Ecology, Physiology, Genetics, Applied Importance and Control. Sofia: Pensoft Publishers; 2000:222.

7. Clements AN: The Biology of Mosquitoes. Sensory Reception and Behaviour Volume 2. Wallingford: CABI Publishing; 1999:752.

8. Harbach RE, Dahl C, White GB: Culex (Culex) pipiens Linnaeus (Diptera, Culicidae) - concepts, type designations, and description. Proc Entomol Soc Wash 1985, 87:1-24.

9. Harbach RE, Harrison BA, Gad AM: Culex (Culex) molestus Forskål (Diptera, Culicidae) - neotype designation, description, variation, and taxonomic status. Proc Entomol Soc Wash 1984, 86:521-542.
10. Byrne K, Nichols RA: Culex pipiens in London Underground tunnels: differentiation between surface and subterranean populations. Heredity 1999, 82:7-15.

11. Huang S, Molaei G, Andreadis TG: Genetic insights into the population structure of Culex pipiens (Diptera: Culicidae) in the Northeastern United States by using microsatellite analysis. Am J Trop Med Hyg 2008, 79:518-527.

12. Gomes B, Sousa CA, Novo MT, Freitas FB, Alves R, Corte-Real AR, Salqueiro P, Donnelly M, Almeida AP, Pinto J: Asymmetric introgression between sympatric molestus and pipiens forms of Culex pipiens (Diptera: Culicidae) in the Comporta region. Portugal. BMC Evol Biol 2009, 9:262.

13. Nudelman S, Galun R, Kitron U, Spielman A: Physiological characteristics of Culex pipiens populations in the Middle East. Med Vet Entomol 1988, 2:161-169.

14. Chevillon C, Eritja R, Pasteur N, Raymond M: Commensalism, adaptation and gene flow: mosquitoes of the Culex pipiens complex in different habitats. Genet Res 1995, 66:147-157.

15. Kilpatrick AM, Kramer LD, Jones MJ, Marra PP, Daszak P, Fonseca DM: Genetic influences on mosquito feeding behavior and the emergence of zoonotic pathogens. Am J Trop Med Hyg 2007, 77:667-671.

16. Spielman A: Structure and seasonality of nearctic Culex pipiens populations. Ann NY Acad Sci 2001, 951:220-234.

17. Kilpatrick AM, Kramer LD, Jones MJ, Marra PP, Daszak P: West Nile virus epidemics in North America are driven by shifts in mosquito feeding behavior. PLOS Biol 2006, 4:e82.

18. Toma L, Cipriani M, Goffredo M, Romi R, Lelli R: First report on entomological field activities for the surveillance of West Nile disease in Italy. Vet Ital 2008, 44:499-512.

19. Almeida APG, Freitas FB, Novo MT, Sousa CA, Rodrigues JC, Alves R, Esteves $A$ : Mosquito surveys and West Nile virus screening in two different areas of Southern Portugal, 2004-2007. Vector-Borne Zoonotic Dis 2010, 10:673-680

20. Calzolari M, Bonilauri P, Bellini R, Albieri A, Defilippo F, Maioli G, Galletti G, Gelati A, Barbieri I, Tamba M, Lelli D, Carra E, Cordioli P, Angelini P, Dottori M: Evidence of simultaneous circulation of West Nile and Usutu viruses in mosquitoes sampled in Emilia-Romagna region (Italy) in 2009. PLOS ONE 2010, 5:e14324

21. Balenghien T, Fouque F, Sabatier P, Bicout DJ: Theoretical formulation for mosquito host-feeding patterns: Application to a West Nile virus focus of southern France. J Med Entomol 2011, 48:1076-1090.

22. Muñoz J, Ruiz S, Soriguer R, Alcaide M, Viana DS, Roiz D, Vázquez A, Figuerola J: Feeding patterns of potential West Nile virus vectors in South-west Spain. PLOS ONE 2012, 7:e39549.

23. Osório HC, Zé-Zé L, Alves MJ: Host-feeding patterns of Culex pipiens and other potential mosquito vectors (Diptera: Culicidae) of West Nile virus (Flaviviridae) collected in Portugal. J Med Entomol 2012, 49:717-721.

24. Rappole JH, Hubálek Z: Migratory birds and West Nile virus. J App/ Microbiol 2003, 94:47-58.

25. Hubálek Z: Mosquito-borne viruses in Europe. Parasitol Res 2008, 103:29-43.

26. Peel MC, Finlayson BL, McMahon TA: Updated world map of the KöppenGeiger climate classification. Hydrol Earth Syst Sci Discuss 2007, 4:1633-1644.

27. Sudia WD, Chamberlain RW: Battery-operated light trap. An improved model. Mosq News 1962, 22:126-129.

28. Ribeiro H, Ramos HC: Identification keys of the mosquitoes (Diptera: Culicidae) of Continental Portugal, Acores and Madeira. Eur Mosa Bull 1999, 3:1-11.

29. Donnelly MJ, Cuamba N, Charlwood JD, Collins FH, Townson H: Population structure in the malaria vector, Anopheles arabiensis Patton, in East Africa. Heredity 1999, 83:408-417.

30. Smith JL, Fonseca DM: Rapid assays for identification of members of the Culex (Culex) pipiens complex, their hybrids, and other sibling species (Diptera: Culicidae). Am J Trop Med Hyg 2004, 70:339-345.

31. Banks MA, Eichert W, Olsen JB: Which genetic loci have greater population assignment power? Bioinformatics 2003, 19:1436-1438.

32. Pritchard JK, Stephens M, Donnelly P: Inference of population structure using multilocus genotype data. Genetics 2000, 155:945-959.

33. Bahnck CM, Fonseca DM: Rapid assay to identify the two genetic forms of Culex (Culex) pipiens L. (Diptera: Culicidae) and hybrid populations. Am J Trop Med Hyg 2006, 75:251-255. 
34. Gomes B, Kioulos E, Papa A, Almeida APG, Vontas J, Pinto J: Distribution and hybridization of Culex pipiens forms in Greece during the West Nile virus outbreak of 2010. Infect Genet Evol 2013, 16:218-225.

35. Simões MJ, Próspero Ml, Henrique R: Optimização da técnica ELISA "two sites" utilizada na identificação de refeições sanguíneas de mosquitos. Rev Port Doenc Infec 1995, 18:225-229.

36. Hamer GL, Kitron UD, Goldberg TL, Brawn JD, Loss SR, Ruiz MO, Hayes DB, Walker ED: Host selection by Culex pipiens mosquitoes and West Nile virus amplification. Am J Trop Med Hyg 2009, 80:268-278.

37. Hall TA: BioEdit: a user-friendly biological sequence alignment editor and analysis program for Windows 95/98/NT. Nucleic Acids Symp Ser 1999, 41:95-98.

38. Evanno G, Regnaut S, Goudet J: Detecting the number of clusters of individuals using the software structure: a simulation study. Mol Ecol 2005, 14:2611-2620.

39. Jakobsson M, Rosenberg NA: CLUMPP: a cluster matching and permutation program for dealing with label switching and multimodality in analysis of population structure. Bioinformatics 2007, 23:1801-1806.

40. Vähä J-P, Primmer CR: Efficiency of model-based Bayesian methods for detecting hybrid individuals under different hybridization scenarios and with different numbers of loci. Mol Ecol 2006, 15:63-72.

41. Nei M: Molecular Evolutionary Genetics. New York: Colombia University Press; 1987:512.

42. Goudet J: FSTAT (version 1.2): A computer program to calculate F-statistics. J Hered 1995, 86:485-486.

43. Kalinowski ST: HP-RARE 1.0: a computer program for performing rarefaction on measures of allelic richness. Mol Ecol Notes 2005, 5:187-189.

44. Excoffier L, Laval G, Schneider S: Arlequin (version 3.0): an integrated software package for population genetics data analysis. Evol Bioinform Online 2005, 1:47-50.

45. Slatkin $M$, Excoffier $L$ : Testing for linkage disequilibrium in genotypic data using the Expectation-Maximization algorithm. Heredity 1996, 76:377-383

46. Van Oosterhout C, Hutchinson W, Wills D, Shipley P: Micro-Checker: software for identifying and correcting genotyping errors in microsatellite data. Mol Ecol Notes 2004, 4:535-538.

47. VassarStats: Web Site for Statistical Computation. [http://vassarstats.net/index. $\mathrm{html}$.

48. Holm S: A simple sequentially rejective multiple test procedure. Scand J Stat 1979, 6:65-70.

49. World Health Organization: Manual on Practical Entomology in Malaria. Part II: Methods and Techniques Geneva. Geneva; 1975:191.

50. Molaei G, Andreadis TG, Armstrong PM, Anderson JF, Vossbrinck CR: Host feeding patterns of Culex mosquitoes and West Nile virus transmission, northeastern United States. Emerg Infect Dis 2006, 12:468-474.

51. Ribeiro H, Pires CA, Ramos HC, Capela RA: Research on the mosquitoes of Portugal (Diptera, Culicicae). VIII- On the occurrence of Culex (Culex) molestus Forskål, 1775. J Soc Cienc Med Lisb 1983, 147:185-188.

52. Huang S, Hamer GL, Molaei G, Walker ED, Goldberg TL, Kitron UD, Andreadis TG: Genetic variation associated with mammalian feeding in Culex pipiens from a West Nile virus epidemic region in Chicago, Illinois. Vector-Borne Zoonotic Dis 2009, 9:637-642.

53. Sousa CA: Malaria vectorial capacity and competence of Anopheles atroparvus Van Thiel, 1927 (Diptera, Culicidae): Implications for the potential re-emergence of malaria in Portugal. PhD thesis. Universidade Nova de Lisboa, Instituto de Higiene e Medicina Tropical; 2008.

54. Formosinho P, Santos-Silva MM, Santos A, Melo P, Encarnação V, Santos N, Nunes T, Agrícola R, Portas M: O vírus West Nile em Portugal - estudos de vigilância epidemiológica. Rev Port. Cienc Vet 2006, 101:61-68.

55. Wheeler SS, Barker CM, Fang Y, Veronica Armijos M, Carroll BD, Husted S, Johnson WO, Reisen WK: Differential Impact of West Nile virus on California Birds. Condor 2009, 111:1-20.

56. Komar N, Langevin S, Hinten S, Nemeth N, Edwards E, Hettler D, Davis B, Bowen $\mathrm{R}$, Bunning M: Experimental infection of North American birds with the New York 1999 strain of West Nile virus. Emerg Infect Dis 2003, 9:311-322.

57. Molaei G, Andreadis TG, Armstrong PM, Bueno R Jr, Dennett JA, Real SV, Sargent C, Bala A, Randle Y, Guzman H, Da Rosa AT, Wuithiranyagool T, Tesh RB: Host feeding pattern of Culex quinquefasciatus (Diptera: Culicidae) and its role in transmission of West Nile virus in Harris County, Texas. Am J Trop Med Hyg 2007, 77:73-81.

doi:10.1186/1756-3305-6-93

Cite this article as: Gomes et al:: Feeding patterns of molestus and pipiens forms of Culex pipiens (Diptera: Culicidae) in a region of high hybridization. Parasites \& Vectors 2013 6:93.

\section{Submit your next manuscript to BioMed Central and take full advantage of:}

- Convenient online submission

- Thorough peer review

- No space constraints or color figure charges

- Immediate publication on acceptance

- Inclusion in PubMed, CAS, Scopus and Google Scholar

- Research which is freely available for redistribution

Submit your manuscript at www.biomedcentral.com/submit
C) BioMed Central 